\title{
Asthma in the Primary Care Setting
}

\author{
Tianshi David Wu, MD, MHS, Emily P. Brigham, MD, MHS, Meredith C. McCormack, MD, \\ MHS $^{*}$ \\ Division of Pulmonary and Critical Care Medicine, Johns Hopkins University School of Medicine, \\ 1830 East Monument Street, 5th Floor, Baltimore, MD 21205, USA
}

\section{Keywords}

Asthma; Review; Outpatient; Ambulatory; Treatment; Diagnosis

Asthma is a chronic disease principally characterized by episodic wheeze, cough, and breathlessness resulting from airway hyperresponsiveness and inflammation. It is one of the most common chronic lung diseases in the United States, affecting approximately $8 \%$ of adults, or about 20 million individuals. ${ }^{1,2}$

Consequently, asthma is frequently encountered in the primary care setting. In the vast majority of cases, asthma is successfully managed by the generalist, and most individuals with asthma are expected to achieve good control. This article summarizes the epidemiology, diagnosis, and chronic and acute management of asthma from the primary care perspective.

\section{EPIDEMIOLOGY}

Asthma is significantly more prevalent in women $(10.4 \%)$ than in men $(6.2 \%)$, those below the poverty line $(11.8 \%)$, and in those who report being an ethnic or racial minority, especially black race (10.2\%) and Puerto Rican Hispanic ethnicity (14.9\%). Geographic prevalence also ranges widely, from $4.9 \%$ to $12.7 \%$ by state. Despite a wide array of treatment options, almost half of adults with asthma report having one or more attacks in the previous year, highlighting the importance of symptom management and disease control. ${ }^{3}$

Asthma is classically thought of as a disease that begins in youth. Although it is true that asthma is most commonly first diagnosed in childhood, it can become clinically apparent at any age. Indeed, a national survey suggests that the rate of first asthma diagnosis for those older than 65 (3.1\% per year) is not substantially different than those between 18 and 34 (4.0\% per year). ${ }^{4}$ The estimated prevalence of asthma among adults over 65 years of age is $7 \%$, which is similar to the overall prevalence. History of prematurity, early lung infections, rhinitis, smoking, and obesity are all risk factors for adult-onset asthma. ${ }^{5-7}$ Therefore, the onset of chronic cough in an older patient should not dissuade the clinician from considering asthma.

\footnotetext{
*Corresponding author. mmccor16@jhmi.edu.
} 


\section{DIAGNOSIS}

The confident diagnosis of asthma requires an integration of patient-reported symptoms and pulmonary function testing. Because the symptoms of asthma are often nonspecific and can be precipitated by other disease processes, the exclusion of diseases that mimic asthma is important, especially in older individuals, who may be more likely to have alternate conditions. A suggested diagnostic model of asthma is included (Fig. 1).

\section{History}

Common symptoms of asthma are wheeze, chest tightness, and cough. These symptoms are often episodic and may vary in intensity. The variability in symptoms often corresponds to changes in exposures, such as allergens, airway irritants, or respiratory infections. Some patients experience bronchoconstriction in response to exercise, and this can result in asthma symptoms. Individuals with uncontrolled disease may present with chronic symptoms at rest. Chest tightness is rarely the sole presenting complaint and should increase suspicion for cardiac disease. ${ }^{8}$ Individuals with asthma often have concurrent rhinitis and sinusitis, and allergic rhinitis is a risk factor for incident asthma. ${ }^{9}$ The presence of upper airway symptoms, which are thought to represent different manifestations of a common allergic pathophysiology, should be elicited.

Providers should inquire about potential exposures that worsen the patient's respiratory complaints. Identifiable triggers increase the probability of underlying asthma. ${ }^{10}$ Allergens are commonly recognized triggers and may be seasonal (typically outdoor) or perennial (typically indoor). The distribution and timing of outdoor allergen exposure are highly variable across the United States. Outdoor allergens typically consist of forms of pollen and can be from trees, grass, and weeds, which are detectable at various times throughout the year. Perennial allergens include sources such as dust mites, mice, cockroaches, molds, and animal dander from pets. Other nonallergic triggers include cigarette use, secondhand smoke exposure, irritants, perfumes or strong odors, extremes of temperature, exercise, or psychosocial distress. Occupational exposures can lead to the onset of asthma (occupational asthma) or worsening of existing asthma (work-exacerbated asthma). ${ }^{11,12}$ It is important to inquire about workplace exposures in relationship to asthma diagnosis and fluctuation in symptoms (eg, differences in symptoms between weekdays and weekends ${ }^{13}$ or during time away from work). Changes in respiratory symptoms during travel are suggestive of environmental sensitivity and support a potential diagnosis of asthma.

Table 1 lists common asthma mimics and associated symptoms. Depending on the patient, additional history evaluating these conditions may be obtained. In particular, for the adult patient presenting with asthmalike symptoms, "cardiac asthma," wheezing as the result of unrecognized heart failure and consequent volume overload, and chronic obstructive pulmonary disease (COPD) should be considered. It is additionally possible for these conditions to coexist with asthma. 


\section{Physical Examination}

The physical examination is most useful in assessing for the presence of comorbid or mimicking conditions. A pulmonary examination in a patient with asthma is often normal. Expiratory wheezing may be present, but is neither sensitive nor specific for this condition. Inspiratory wheezing is not typical and may suggest an additional or alternate diagnosis. Similarly, crackles should elicit consideration of alternative diagnoses. Patients may have signs of concurrent rhinitis or postnasal drip. A skin examination may reveal eczema. Finally, a cardiac examination should be performed to evaluate for signs of heart failure.

\section{Diagnostic Testing}

If the history and physical examination suggest asthma as a likely diagnosis, the next step is to perform spirometry before and after bronchodilator administration to evaluate for the 2 key criteria central to asthma diagnosis: expiratory airflow obstruction and variability in airflow limitation. Spirometry demonstrating both expiratory airflow obstruction and full reversal of airflow obstruction following bronchodilator administration supports a diagnosis of asthma. However, because variability in symptoms and airflow limitation is a key feature of asthma, spirometry is frequently normal when asthma is well controlled. Furthermore, some patients with asthma who present with expiratory airflow obstruction may not fully reverse after bronchodilator administration, because of a greater disease severity at presentation or because of airway remodeling in chronically uncontrolled asthma. As partial reversibility is also a feature of COPD or asthma-COPD overlap, these other conditions should be considered. In such situations, spirometry cannot reliability distinguish between asthma and COPD.

The presence of airflow obstruction is defined by a ratio of fractional exhaled volume in the first second $\left(\mathrm{FEV}_{1}\right)$ to the total volume forcefully exhaled $(\mathrm{FVC})$ less than the lower limit of normal (LLN). The LLN is based on distributions from healthy normal populations and is preferred to using a fixed cutoff (eg, 70\%) because the LLN accounts for the expected decline in $\mathrm{FEV}_{1} / \mathrm{FVC}$ that occurs with aging. Postbronchodilator responsiveness is defined by an increase in $\mathrm{FEV}_{1}$ or $\mathrm{FVC}$ by greater than $12 \%$ and greater than $200 \mathrm{~mL}$ after bronchodilator. ${ }^{14}$ These thresholds are provided by guidelines, ${ }^{15,16}$ which acknowledge clinical context should be taken into account when interpreting test results. For example, a patient who has a 10\% improvement in FEV1 after bronchodilator and who demonstrates improvement in prebronchodilator $\mathrm{FEV}_{1}$ after a trial of inhaled corticosteroids (ICS) would have had a clinically significant response that is highly consistent with a diagnosis of asthma, despite falling short of the $12 \%$ and $200-\mathrm{mL}$ threshold.

If spirometry is normal, but clinical suspicion for asthma remains, repetition of spirometry at another time point is essential, because at least one episode of obstruction should be documented to support the diagnosis of asthma. Variability in airflow limitation, if not identifiable by reversibility on spirometry, may also be documented by serial testing with a peak flow meter. The patient is instructed to record the best of 3 attempted peak flows twice daily (generally morning and evening) over a 2-week period or more often during periods of respiratory symptoms. Excessive variability in peak flows in the setting of normal spirometry can also diagnose variable airflow limitation; this is defined by a 1-week average 
of each day's highest to lowest recorded measurement, divided by the day's average, greater than $10 \% .^{15}$

Bronchoprovocation testing for airway hyperresponsiveness, such as a methacholine challenge, has a low specificity for asthma. Airway hyperresponsiveness is present in other pulmonary conditions, including COPD, and in the normal population, where the prevalence has ranged from $4 \%$ to $37 \% .{ }^{17}$ This test has consequently become less used in the confirmation of asthma but retains a role in select populations to rule out asthma given its high negative predictive value, which has been reported to approach $100 \%{ }^{18,19}$

Unless the patient is highly symptomatic at initial presentation, the preferred approach is a stepwise diagnostic process that involves spirometry or peak flow testing to establish both obstruction and variable airflow limitation. Identifying asthma-related obstruction is challenging when patients are already on asthma medications. A recent Canadian study suggested that as many as one-third of individuals with a physician diagnosis of asthma did not truly have it. These patients were less likely to have had formal testing for airflow limitation, and study findings reinforce the value of objective testing to support the diagnosis of asthma. ${ }^{20}$

Radiographic studies and blood tests are generally unnecessary in the diagnostic process unless there is suspicion for an alternative diagnosis. Elevations in eosinophils, immunoglobulin $\mathrm{E}$ (IgE), or allergen-specific $\operatorname{IgE}$, although helpful in diagnosing allergic disease or when considering advanced therapies, is neither sensitive nor specific for the initial diagnosis of asthma. Fractional exhaled nitric oxide (FeNO) is a marker of eosinophilic airway inflammation but is typically unnecessary in the diagnosis of asthma.

\section{Variants of Asthma}

Individuals with cough-variant asthma manifest cough as their primary symptom. ${ }^{21,22}$ It is thought that the cough is a neural response to bronchoconstriction rather than from mucus secretion, but the exact mechanism is unknown. ${ }^{23}$ These individuals typically do not complain of wheeze, and the differential necessarily revolves around other causes of chronic cough.

Exercise-induced asthma occurs in individuals who experience symptoms after vigorous physical activity due to excessive airway sensitivity to cold or dry air that occurs during exercise-associated hyperventilation. ${ }^{24}$ These individuals complain of typical asthma symptoms shortly after finishing exercise that lasts for up to 1 hour afterward.

Aspirin-exacerbated respiratory disease (AERD) is asthma that is precipitated or worsened by medications that inhibit cyclo-oxygenase 1 , an enzyme involved in degradation of proinflammatory leukotrienes. It is also known as Samter's triad, which describes the combination of asthma, aspirin sensitivity, and sinus disease with nasal polyposis. The condition is somewhat of a misnomer, in that all nonsteroidal anti-inflammatory drugs, not only aspirin, can precipitate worsening. AERD is typically more severe and uncontrolled than other forms of asthma; it is present in approximately $14 \%$ of patients with severe asthma and $7 \%$ of all comers with asthma. ${ }^{25}$ 
Vocal cord dysfunction (VCD) is not a variant of asthma but deserves special mention, because it is a classic mimic of asthma that may also be a comorbid condition. In VCD, there is paradoxic closure of the vocal cords mainly during inspiration, causing wheezing and dyspnea. ${ }^{26}$ VCD should be considered in patients who have sudden onset wheezing, occurring predominantly during inspiration, which is short in duration with limited or no response to asthma medications. For those with VCD, including those with coexisting asthma, speech therapy by a therapist knowledgeable about VCD can be very beneficial, and it is important to recognize this condition in order to provide treatment.

\section{MANAGEMENT}

Because asthma by definition demonstrates variability in symptoms and airflow limitation, its successful management involves continual reassessment over time to optimize disease control and treat underlying inflammation while minimizing side effects from prescribed medications. At each visit, the clinician should assess symptoms, risk of worsening, medication tolerance and adherence, and comorbidities. Fig. 2 lists atypical stepwise approach for a patient with established or newly diagnosed asthma. With optimal treatment, the vast majority of patients can expect to be well controlled.

\section{Assessment of Asthma Control Versus Asthma Severity}

Asthma severity may be assessed before the initiation of medical therapy, based on lung function, symptom frequency, and history of exacerbations. Severity is helpful in guiding initial therapeutic decisions and is classified as intermittent, mild persistent, moderate persistent, or severe persistent. The classification of mild intermittent is no longer recommended because it implies that other severities cannot also be intermittently symptomatic. Importantly, asthma severity is not a static property and should be reassessed at each visit with reclassification based on the magnitude of treatment needed to control, or alleviate the symptoms of, asthma. Asthma severity reflects the intensity of the overall disease process, and changes in asthma severity may indicate new environmental exposures, comorbidities, or advancing disease.

At each visit, a patient's asthma control, the frequency of a patient's asthma symptoms and their associated effects, should be assessed. Both EPR-3and GINA suggest assessing control by 4 frequency questions over a 2- to 4-week recall: days with asthma symptoms, days with nocturnal awakening, days of activity limitation due to asthma, and days of rescue inhaler use outside of those taken before exercise. ${ }^{15,16}$

Asthma is considered well controlled if there are 2 or less days of symptoms, 2 or less days of rescue inhaler use, and no days nocturnal awakening or activity limitation due to asthma, over the prior 2 weeks. The use of patient-completed questionnaires that assess asthma control, such as the Asthma Control Test or Asthma Control Questionnaire, can be applied in clinical settings and provides improved sensitivity to detect changes in control over time. 27,28

Although both control and severity may be expected to change over time, they are distinct concepts: a patient with uncontrolled asthma does not necessarily have severe asthma. 
Furthermore, several factors may confound assessment, including improper inhaler technique, barriers to adherence, ongoing exposure to triggers, and contributing comorbidities, all of which should be queried in the setting of poor control. Importantly, asthma control is more relevant than asthma severity for predicting risk of future exacerbation. ${ }^{29}$

Finally, prebronchodilator spirometry, with attention to $\mathrm{FEV}_{1}$, should be routinely performed. Individuals with prebronchodilator $\mathrm{FEV}_{1}$ below the LLN likely represent uncontrolled disease and are at increased risk for subsequent exacerbation. ${ }^{30,31}$ Tailoring asthma therapy based on sputum eosinophilia or FeNO has been associated with reduced exacerbations, but there is insufficient evidence to support implementing this in clinical practice. $^{32}$

\section{Nonpharmacologic Interventions}

Avoidance of triggers is a cornerstone of asthma management. Common triggers and strategies to address them are included in Table 2. In those with seasonal allergies or sensitivity to air pollution, patients are advised to stay indoors and close windows during periods of high pollen counts or poor outdoor air quality, respectively. Importantly, the timing of pollen avoidance is specific to each patient's aeroallergen sensitization profile, which should be determined if there is a strong history of seasonal allergies and requires referral to an allergist. Avoidance of secondhand smoke and smoking cessation are emphasized. ${ }^{33}$ Avoidance of indoor allergens, targeting specific allergens to which the patient is sensitized, is recommended but is difficult to implement because of difficulties in achieving total allergen remediation and cost of interventions. ${ }^{34,35}$

A common option is to treat symptomatic gastroesophageal reflux disease, under the premise that acid reflux may precipitate bronchoconstriction. However, objective evidence of efficacy in improving asthma control or severity in adults is inconsistent. ${ }^{36}$ Similarly, treatment of allergic rhinitis may also be attempted, although benefit in asthma for those who are already on ICS may be small. ${ }^{37}$

Adults with asthma should receive an early dose of the PPSV23 vaccine before age $65 .{ }^{38}$ Recommendations are otherwise not different from healthy adults.

As part of overall health maintenance, overweight or obese patients should be counseled on weight reduction, and all patients should be encouraged to consume a healthy diet. Interventional studies have demonstrated improvement in asthma severity and control with weight reduction, with magnitude in the order of 10 to $15 \mathrm{kgs}^{39}$

\section{Pharmacologic Therapy}

Pharmacologic therapy is broadly divided into controller medications and rescue medications. Asthma treatment guidelines organize drug treatment for asthma into therapeutic steps, with higher steps reflecting more intense controller treatment. A diagram of recommended medications adapted from GINA is included in Fig. 3. More detailed charts that include alternative options are available from the source publications. ${ }^{15,16}$ 


\section{Controller Medications}

The general goal of controller therapy is to intervene in the inflammatory process underlying asthma and to prevent the development of irreversible airway remodeling. To this end, controller therapies are offered to all individuals with persistent asthma, even those with mild disease. Patients should be counseled that asthma is a chronic condition, and that the absence of asthma symptoms is the result of effective controller use. The conceptualization of "no symptoms, no asthma" is strongly associated with worse outcomes. ${ }^{40}$

ICS form the backbone of controller therapy. Common side effects include oral thrush, which may be ameliorated through the use of a spacer device and rinsing the mouth after ICS use, and dysphonia, which may be anecdotally improved by switching to a different delivery device. Long-acting beta agonists (LABA) or leukotriene modifiers may be added to ICS if control is suboptimal, with the former option more effective than the latter. ${ }^{41,42}$ Long-acting muscarinic antagonists, which are commonly used in COPD, do not appear to be superior to LABA as add-on therapy in asthma and are typically reserved for severe disease. ${ }^{43,44}$ Importantly, there is an absolute contraindication to LABA monotherapy (ie, without concurrent ICS) because of a consistent association with increased asthma-related mortality; LABA monotherapy is inappropriate and should never be prescribed for a patient with asthma.

\section{Rescue Medications}

A rescue inhaler in the form of albuterol should be offered to all patients. This short-acting medication provides immediate bronchodilation in patients with acute symptoms and may be performed up to 4 times a day. To an adult patient with appropriate instruction, albuterol delivered by metered-dose inhaler (MDI) without spacer, MDI with spacer, or nebulizer is equally effective. However, in practice, spacers and nebulizers can deliver medication more reliably. ${ }^{45,46}$ Patients with intermittent asthma may achieve control with a short-acting betaagonist alone; those with persistent asthma (ie, use their albuterol inhaler more than twice weekly to resolve symptoms) necessitate addition of ICS.

The importance of verifying inhaler technique and adherence cannot be overstated. As many as two-thirds of patients have errors in MDI use, leading to suboptimal delivery of medication and worse asthma control. ${ }^{47,48}$ Videos demonstrating the proper use of an MDI and other devices are available from the US Centers for Disease Control and Prevention $(\mathrm{CDC})^{49}$ and the American Lung Association. ${ }^{50}$ Verification of inhaler technique will only become more important as manufacturers develop increasingly specialized delivery devices.

Similarly, medication adherence, the proportion of scheduled doses that are actually taken, should also be queried. Dose counters and pharmacy data, if logistically possible, are valuable objective sources of adherence information. Studies estimate average adult ICS adherence in the range of $22 \%$ to $63 \%$, suggesting that true corticosteroid doses may be as much as half the amount on a patient's medication list. ${ }^{51}$ Aside from older age and belief in medication necessity, there are no consistent factors that are associated with nonadherence. ${ }^{52}$ Unfortunately, very few adherence interventions have shown improvement in asthma outcomes, highlighting the complexity of this important aspect of asthma care. ${ }^{51,53}$ 


\section{Initiating and Modifying Treatment}

For the patient who is beginning therapy, professional recommendations provide guidance regarding medication initiation based on severity assessment. ${ }^{15,16}$

For the well-controlled patient who is already on therapy, symptom free over the past 3 months, deescalation may be considered. The goal is to decrease risk of adverse effects associated with inappropriately intensive treatment and to find the therapeutic "floor," allowing adequate ascertainment of disease severity. The patient should be counseled to return to the higher treatment step if there is evidence of worsening control, including decreased peak flow or increased symptoms.

For the uncontrolled patient who is already on therapy, a recurrent search for precipitating factors may reveal environmental changes (providing an opportunity for environmental counseling) or a lapse in inhaler adherence (providing an opportunity to reinforce inhaler need and adherence). Temporary or permanent escalation of therapy by 1 to 2 steps may be necessary to regain or establish control. Symptoms that continue to worsen and are unresponsive to escalation in therapy should prompt a search for an alternative or overlapping diagnosis (see Table 1).

In selected cases, if a patient is thought to have uncontrolled disease because of technical (cannot reliably coordinate the actuation with inspiration, necessary for MDI) or physiologic reasons (inability to take in a rapid breath, necessary for dry powder inhalers), he or she may be switched to a different delivery device of the same equivalent dose of medication.

Overall, there is no delivery device that is clearly superior to another among all patients.

\section{Self-Management and the Asthma Action Plan}

Asthma self-management involves empowerment of the patient to avoid triggers and modify his or her treatment regimen in response to changes in symptoms or in lung function.

The foundation of asthma self-management is an asthma action plan. Patients are provided with a peak flow meter, and a personal best measurement for that device is determined during a period of good control; the use of prediction equations for peak flows do not perform well, likely due to variation in accuracy between devices and patients. ${ }^{54}$ Patients then check their peak flows daily or when experiencing worsened symptoms, and depending on the value are classified as in the green ( $\$ 80 \%$ of personal best), yellow $(50 \%-79 \%$ of personal best), or red zone ( $<50 \%$ of personal best). Alternatively, patients may be classified based solely on symptoms, whereby experiencing any wheezing, cough, or nocturnal awakening classifies a patient in the yellow zone, and experiencing severe symptoms, including inability to perform any of their usual activities or disabling shortness of breath, classifies a patient in the red zone. A combination of both approaches is encouraged, particularly in patients with poor recognition of symptoms progression.

Options for yellow zone interventions vary, but generally involve rescue inhaler use, notification of the physician and possible step-up in controller medication, and initiation of an oral corticosteroid if symptoms and peak flow do not normalize within a specific time period. Doubling of ICS in the yellow zone does not appear to be effective, but quadrupling 
of ICS has been shown to reduce risk of progressing to oral corticosteroids or having an acute asthma visit by $20 \%$, at the expense of increased dysphonia and oral thrush. ${ }^{55}$ Patients in the red zone should immediately use their rescue inhaler and contact the physician or present to an emergency department. Physicians may consider a step-up in controller regimen relative to preexacerbation regimen.

Self-management strategies have been shown to prevent exacerbations, decrease asthmarelated health care utilization, and improve quality of life. ${ }^{56}$ Using peak flow measurement or symptoms to guide management appears to be generally equivalent. ${ }^{57}$ Asthma action plan forms are available from the CDC, the National Institutes of Health, and the American Lung Association. ${ }^{58-60}$

\section{Other Treatment Options in Severe Asthma}

Additional therapeutic options may be warranted in severe asthma, and consideration of advanced therapies should trigger referral to a pulmonologist and/or an allergistimmunologist. ${ }^{61}$

Recent advances in biologic therapies have resulted in several new medications available for severe asthma with emerging treatments in the pipeline. The indications for these are based on individual patient characteristics, and such medications are typically administered in consultation with a subspecialist.

The allergic inflammatory pathway is a common target. Omalizumab is an antibody against serum IgE, an immunoglobulin that interfaces with mast cells, eosinophils, and basophils in the allergic cascade. ${ }^{62}$ It is approved in patients with moderate to severe asthma with documented allergen sensitivity that is not controlled with ICS and is administered every 2 to 4 weeks. Mepolizumab, reslizumab, and benralizumab are antibodies targeting the interleukin-5 pathway, involved in recruitment and activation of eosinophils. ${ }^{63-65}$ They are approved in the United States for patients with severe asthma and persistent eosinophilia despite adequate ICS therapy and are administered every 4 to 8 weeks in health care settings, subcutaneously for mepolizumab and benralizumab, and intravenously for reslizumab. For patients with difficult-to-control asthma and prominent allergies, subcutaneous immunotherapy has been shown to reduce asthma severity, need for systemic corticosteroids, and need for rescue inhaler use. ${ }^{66}$ There is a small risk of anaphylaxis, but literature is insufficient to comment on its magnitude and severity.

Bronchial thermoplasty (BT) is an endoscopic procedure whereby radiofrequency heat energy is applied to the airways, ablating airway smooth muscle and reducing its ability to cause bronchoconstriction. ${ }^{67}$ Evidence suggests that BT reduces exacerbations, reduces asthma-related health care utilization, and improves quality of life in individuals with severe asthma. ${ }^{68}$ This procedure is typically performed by experienced centers only and is associated with transient increase in exacerbation risk during the treatment course.

\section{Risk Assessment and Follow-Up}

At the conclusion of the visit, the risk of future asthma exacerbation or poor outcomes is assessed. Major factors that are currently considered are uncontrolled disease, abnormal 
$\mathrm{FEV}_{1}$, unmitigated recent exposure to a known personal trigger, and history of exacerbations requiring hospitalization or intubation. Patients who display one or more of these features, including those who had therapy modification in the present visit, should have a short interval follow-up, generally within 2 to 6 weeks. Patients at lower risk can be seen every 3 months, and these visits may be spaced further to every 6 months or annually pending optimization of therapy and disease stability. The optimal interval for repeat lung function testing is unknown, but is recommended by consensus opinion to be every 1 to 2 years in those with stable disease, with attention to development of fixed obstruction, which is suggestive of chronically inadequate control.

\section{ACUTE OUTPATIENT EXACERBATIONS OF ASTHMA}

For the outpatient presenting with acute worsening of asthma symptoms, a focused history and physical examination will readily guide management. On history, recent sick contacts, abrupt discontinuation of controller therapies, and exposure to personal asthma triggers should be inquired about. Most acute exacerbations are precipitated by viral respiratory infections, in particular, rhinovirus. ${ }^{69}$ The pace of symptom worsening should be documented. On examination, signs of infection and overall respiratory status should be evaluated. Hypoxemia, use of accessory muscles, inspiratory and expiratory wheezing, and absence of wheezing associated with respiratory discomfort are worrisome symptoms. If the patient is able to safely perform respiratory maneuvers and does not require immediate emergency referral, serial peak flow determinations should be performed before and after inoffice albuterol. Radiographic abnormalities are rare in an uncomplicated exacerbation, and chest imaging is not routinely performed.

Nebulizers and MDIs (with spacers) are equivalent when used in the acute setting and are dependent on preference. ${ }^{70}$ The optimal dosing of albuterol appears to be 2.5 -mg aliquots every 20 minutes (for nebulizer) or 3 to 5 puffs (for MDI) every 10 minutes, up to 3 times. 71,72 In addition to removal from exposure to triggers, oral corticosteroids are the mainstay treatment of asthma exacerbation and intervention in the underlying inflammatory response. Doses higher than 40 to $100 \mathrm{mg}$ of prednisone daily or longer than 5 to 10 days do not appear to be superior. ${ }^{73}$ In general, tapering is unnecessary. If symptoms and peak flow have returned to baseline on completion of corticosteroids and the inciting factor can be avoided, patients may resume their green zone treatment regimen. Otherwise, maintenance treatment may need to be escalated to the next step of the treatment ladder pending reevaluation, or in selected cases, oral corticosteroids may be extended.

Despite progress made in the protocolization of asthma treatment, decision for referral to the emergency department remains a clinical one, combining consideration of disease trajectory, potential ongoing exposure to trigger, and ability of patient to manage necessary therapies on an outpatient basis. Patients should be seen within 2 weeks after an exacerbation to reassess symptoms, lung function, and appropriateness of current controller therapy. Asthma exacerbations, especially those associated with hospitalization or emergency department treatment, have been associated with long-term declines in lung function, ${ }^{74,75}$ and prevention should be emphasized. 


\section{INDICATIONS FOR SPECIALIST REFERRAL}

With adequate training, the vast majority of asthma may be successfully managed in the primary care setting. ${ }^{76}$ However, specialist referral may be warranted in some cases, especially in patients with persistently uncontrolled or severe asthma, or in patients in whom the diagnosis of asthma is unclear. Involvement of specialist care, through either pulmonology or allergy, has been associated with improved outcomes. ${ }^{76,77}$ Box 1 lists common indications for referral.

\section{Acknowledgments}

Disclosure Statement: This article was supported by NIH grants F32ES028578 (D. Wu), KL2TR001077 (E. Brigham) and M.C. McCormack receives royalties for authorship for UpToDate.

\section{REFERENCES}

1. Villarroel MA, Blackwell DL. Percentage of adults aged 18-64 years with current asthma,* by State-National Health Interview Survey,(Dagger) 2014-2016. Atlanta (GA): Centers Disease Control 1600 Clifton Rd; 2018. 30333 USA.

2. CDC - Asthma - Most recent asthma data. 2018 Available at: https://www.cdc.gov/asthma/ most_recent_data.htm. Accessed September 14, 2018.

3. Mazurek JM. Prevalence of asthma, asthma attacks, and Emergency Department visits for asthma among working adults - national health interview survey, 2011 - 2016. MMWR Morb Mortal Wkly Rep 2018;67 10.15585/mmwr.mm6713a1.

4. Winer RA, Qin X, Harrington T, et al. Asthma incidence among children and adults: findings from the behavioral risk factor surveillance system asthma call-back survey-United States, 2006-2008. J Asthma 2012;49(1):16-22. [PubMed: 22236442]

5. Huovinen E, Kaprio J, Koskenvuo M. Factors associated to lifestyle and risk of adult onset asthma. Respir Med 2003;97(3):273-80. [PubMed: 12645835]

6. Guerra S, Sherrill DL, Martinez FD, et al. Rhinitis as an independent risk factor for adult-onset asthma. J Allergy Clin Immunol 2002;109(3):419-25. [PubMed: 11897985]

7. Jamrozik E, Knuiman MW, James A, et al. Risk factors for adult-onset asthma: a 14-year longitudinal study. Respirology 2009;14(6):814-21. [PubMed: 19703063]

8. Shen H, Hua W, Wang P, et al. A new phenotype of asthma: chest tightness as the sole presenting manifestation. Ann Allergy Asthma Immunol 2013;111(3):226-7. [PubMed: 23987204]

9. Dixon AE. Rhinosinusitis and asthma: the missing link. Curr Opin Pulm Med 2009; 15(1):19-24. [PubMed: 19077701]

10. Vernon MK, Wiklund I, Bell JA, et al. What do we know about asthma triggers? a review of the literature. J Asthma 2012;49(10):991-8. [PubMed: 23574397]

11. Henneberger PK, Redlich CA, Callahan DB, et al. An official American Thoracic Society statement: work-exacerbated asthma. Am J Respir Crit Care Med 2011;184(3):368-78. [PubMed: 21804122]

12. Tarlo SM, Lemiere C. Occupational asthma. N Engl J Med 2014;370(7):640-9. [PubMed: 24521110]

13. Work-related asthma: number of cases by classification and state, 2009-2012 Available at: https:// wwwn.cdc.gov/eworld/Data/Workrelated_asthma_Number_of_cases_by_classification_and_state_20092012/924. Accessed September 14, 2018.

14. Pellegrino R, Viegi G, Brusasco V, et al. Interpretative strategies for lung function tests. Eur Respir J 2005;26(5):948-68. [PubMed: 16264058]

15. Bateman ED, Hurd SS, Barnes PJ, et al. Global strategy for asthma management and prevention: GINA executive summary (vol 31, pg 143, 2008). Eur Respir J 2018;51(2):143-78. 
16. Busse WW, Boushey HA, Camargo CA, et al. Expert panel report 3: guidelines for the diagnosis and management of asthma. Washington (DC): US Department of Health and Human Services, National Heart Lung and Blood Institute; 2007 p. 1-417.

17. Borak J, Lefkowitz RY. Bronchial hyperresponsiveness. Occup Med (Lond) 2016; 66(2):95-105. [PubMed: 26590957]

18. Cockcroft DW. Direct challenge tests: airway hyperresponsiveness in asthma: its measurement and clinical significance. Chest 2010;138(2, Supplement): 18S-24S. [PubMed: 20668014]

19. Cockcroft DW, Murdock KY, Berscheid BA, et al. Sensitivity and specificity of histamine PC20 determination in a random selection of young college students. J Allergy Clin Immunol 1992;89(1, Part 1):23-30. [PubMed: 1730837]

20. Aaron SD, Vandemheen KL, FitzGerald JM, et al. Reevaluation of diagnosis in adults with physician-diagnosed asthma. JAMA 2017;317(3):269-79. [PubMed: 28114551]

21. Desai D, Brightling C. Cough due to asthma, cough-variant asthma and non-asthmatic eosinophilic bronchitis. Otolaryngol Clin North Am 2010;43(1):123-30. [PubMed: 20172262]

22. Corrao W, Braman S, Irwin R. Chronic cough as the sole presenting manifestation of bronchial asthma. N Engl J Med 1979;300:633-7. [PubMed: 763286]

23. Niimi A Cough and asthma. Curr Respir Med Rev 2011;7(1):47-54. [PubMed: 22081767]

24. McFadden ER, Gilbert IA. Exercise-induced asthma. N Engl J Med 1994;330(19): 1362-7. [PubMed: 8152449]

25. Rajan JP, Wineinger NE, Stevenson DD, et al. Prevalence of aspirin-exacerbated respiratory disease among asthmatic patients: a meta-analysis of the literature. J Allergy Clin Immunol 2015;135(3):676-81.e1. [PubMed: 25282015]

26. Kenn K, Balkissoon R. Vocal cord dysfunction: what do we know? Eur Respir J 2011;37(1):194200. [PubMed: 21205712]

27. Schatz M, Sorkness CA, Li JT, et al. Asthma control test: reliability, validity, and responsiveness in patients not previously followed by asthma specialists. J Allergy Clin Immunol 2006;117(3):549_ 56. [PubMed: 16522452]

28. Juniper EF, O’Byrne PM, Guyatt GH, et al. Development and validation of a questionnaire to measure asthma control. Eur Respir J 1999;14(4):902-7. [PubMed: 10573240]

29. Cockcroft DW, Swystun VA. Asthma control versus asthma severity. J Allergy Clin Immunol 1996;98(6):1016-8. [PubMed: 8977499]

30. Kitch BT, Paltiel AD, Kuntz KM, et al. A single measure of FEV1 is associated with risk of asthma attacks in long-term follow-up. Chest 2004;126(6):1875-82. [PubMed: 15596687]

31. Osborne ML, Pedula KL, O'Hollaren M, et al. Assessing future need for acute care in adult asthmatics: the Profile of Asthma Risk Study: a prospective health maintenance organization-based study. Chest 2007;132(4):1151-61. [PubMed: 17573515]

32. Petsky HL, Cates CJ, Kew KM, et al. Tailoring asthma treatment on eosinophilic markers (exhaled nitric oxide or sputum eosinophils): a systematic review and meta-analysis. Thorax 2018 10.1136/ thoraxjnl-2018-211540.

33. Gautier C, Charpin D. Environmental triggers and avoidance in the management of asthma. J Asthma Allergy 2017;10:47-56. [PubMed: 28331347]

34. GØtzsche PC, Johansen HK. House dust mite control measures for asthma. Cochrane Database Syst Rev 2008;(2). 10.1002/14651858.CD001187.pub3.

35. Platts-Mills TAE. Allergen avoidance in the treatment of asthma and rhinitis. N Engl J Med 2003;349(3):207-8. [PubMed: 12867602]

36. Gibson PG, Henry R, Coughlan JJ. Gastro-oesophageal reflux treatment for asthma in adults and children. Cochrane Database Syst Rev 2003;(1). 10.1002/14651858.CD001496.

37. Taramarcaz P, Gibson PG. Intranasal corticosteroids for asthma control in people with coexisting asthma and rhinitis. Cochrane Database Syst Rev 2003;(3). 10.1002/14651858.CD003570.

38. Kim DK, Riley LE, Hunter P. Recommended immunization schedule for adults aged 19 years or older, United States, 2018. Ann Intern Med 2018;168(3):210-20. [PubMed: 29404596]

39. Juel CT-B, Ali Z, Nilas L, et al. Asthma and obesity: does weight loss improve asthma control? a systematic review. J Asthma Allergy 2012;5:21-6. [PubMed: 22791994] 
40. Halm EA, Mora P, Leventhal H. No symptoms, no asthma: the acute episodic disease belief is associated with poor self-management among inner-city adults with persistent asthma. Chest 2006;129(3):573-80. [PubMed: 16537854]

41. Chauhan BF, Ducharme FM. Addition to inhaled corticosteroids of long-acting beta2-agonists versus anti-leukotrienes for chronic asthma. Cochrane Database Syst Rev 2014;(1). 10.1002/14651858.CD003137.pub5.

42. Ducharme F, Ni Chroinin M, Greenstone I, et al. The addition of long-acting beta2-agonists to inhaled steroids compared to higher doses of inhaled steroids alone as maintenance treatment for chronic asthma. Cochrane Database Syst Rev 2010;(4). 10.1002/14651858.CD005533.pub2.

43. Kew K, Dahri K. Long-acting muscarinic antagonists (LAMA) added to combination long-acting beta2-agonists and inhaled corticosteroids (LABA/ICS) versus LABA/ICS for adults with asthma. Cochrane Database Syst Rev 2016;(1). 10.1002/14651858.CD011721.pub2.

44. Sobieraj DM, Baker WL, Nguyen E, et al. Association of inhaled corticosteroids and long-acting muscarinic antagonists with asthma control in patients with uncontrolled, persistent asthma: a systematic review and meta-analysis. JAMA 2018;319(14):1473-84. [PubMed: 29554174]

45. Newman KB, Milne S, Hamilton C, et al. A comparison of albuterol administered by metered-dose inhaler and spacer with albuterol by nebulizer in adults presenting to an urban emergency department with acute asthma. Chest 2002;121(4): 1036-41. [PubMed: 11948030]

46. Newman SP. Spacer devices for metered dose inhalers. Clin Pharmacokinet 2004;43(6):349-60. [PubMed: 15086274]

47. Sanchis J, Gich I, Pedersen S. Systematic review of errors in inhaler use: has patient technique improved over time? Chest 2016;150(2):394-406. [PubMed: 27060726]

48. Price D, Bosnic-Anticevich S, Briggs A, et al. Inhaler competence in asthma: common errors, barriers to use and recommended solutions. Respir Med 2013; 107(1):37-46. [PubMed: 23098685]

49. CDC - Asthma - Using an asthma inhaler videos. 2018 Available at: https://www.cdc.gov/asthma/ inhaler_video/default.htm. Accessed September 15, 2018.

50. Asthma patient resources and videos. Available at: http://www.lung.org/lung-health-and-diseases/ lung-disease-lookup/asthma/patient-resources-and-videos/. Accessed September 15, 2018.

51. Bårnes CB, Ulrik CS. Asthma and adherence to inhaled corticosteroids: current status and future perspectives. Respir Care 2015 10.4187/respcare.03200.

52. Dima AL, Hernandez G, Cunillera O, et al. Asthma inhaler adherence determinants in adults: systematic review of observational data. Eur Respir J 2015; 45(4):994-1018. [PubMed: 25504997]

53. Gamble J, Stevenson M, Heaney LG. A study of a multi-level intervention to improve nonadherence in difficult to control asthma. Respir Med 2011;105(9): 1308-15. [PubMed: 21511454]

54. Miller MR, Dickinson SA, Hitchings DJ. The accuracy of portable peak flow meters. Thorax 1992;47(11):904-9. [PubMed: 1465746]

55. McKeever T, Mortimer K, Wilson A, et al. Quadrupling inhaled glucocorticoid dose to abort asthma exacerbations. N Engl J Med 2018;378:902-10. [PubMed: 29504499]

56. Gibson PG, Powell H, Wilson A, et al. Self-management education and regular practitioner review for adults with asthma. Cochrane Database Syst Rev 2002;(3). 10.1002/14651858.CD001117.

57. Powell H, Gibson PG. Options for self-management education for adults with asthma. Cochrane Database Syst Rev 2002;(3). 10.1002/14651858.CD004107.

58. Asthma Action Plan | National Heart, Lung, and Blood Institute (NHLBI). Available at: https:// www.nhlbi.nih.gov/health-topics/all-publications-and-resources/asthma-action-plan. Accessed September 17, 2018.

59. CDC - Asthma - tools for asthma control. 2018 Available at: https://www.cdc.gov/asthma/ tools_for_control.htm. Accessed September 17, 2018.

60. Create an asthma action plan | American Lung Association. Available at: https://www.lung.org/ lung-health-and-diseases/lung-disease-lookup/asthma/living-with-asthma/managing-asthma/ create-an-asthma-action-plan.html. Accessed September 17, 2018.

61. Chung KF, Wenzel SE, Brozek JL, et al. International ERS/ATS guidelines on definition, evaluation and treatment of severe asthma. Eur Respir J 2014;43(2): 343-73. [PubMed: 24337046] 
62. Thomson NC, Chaudhuri R. Omalizumab: clinical use for the management of asthma. Clin Med Insights Circ Respir Pulm Med 2012;6:27-40. [PubMed: 22745565]

63. Ortega HG, Liu MC, Pavord ID, et al. Mepolizumab treatment in patients with severe eosinophilic asthma. N Engl J Med 2014;371(13):1198-207. [PubMed: 25199059]

64. Castro M, Zangrilli J, Wechsler ME, et al. Reslizumab for inadequately controlled asthma with elevated blood eosinophil counts: results from two multicentre, parallel, double-blind, randomised, placebo-controlled, phase 3 trials. Lancet Respir Med 2015;3(5):355-66. [PubMed: 25736990]

65. FitzGerald JM, Bleecker ER, Nair P, et al. Benralizumab, an anti-interleukin-5 receptor a monoclonal antibody, as add-on treatment for patients with severe, un-controlled, eosinophilic asthma (CALIMA): a randomised, double-blind, placebo-controlled phase 3 trial. Lancet 2016;388(10056):2128-41. [PubMed: 27609406]

66. Lin SY, Azar A, Suarez-Cuervo C, et al. The role of immunotherapy in the treatment of asthma. Rockville (MD): Agency for Healthcare Research and Quality (US); 2018 Available at: http:// www.ncbi.nlm.nih.gov/books/NBK513535/. Accessed September 16, 2018.

67. Dombret M-C, Alagha K, Boulet LP, et al. Bronchial thermoplasty: a new therapeutic option for the treatment of severe, uncontrolled asthma in adults. Eur Respir Rev 2014;23(134):510-8. [PubMed: 25445950]

68. Chupp G, Laviolette M, Cohn L, et al. Long-term outcomes of bronchial thermoplasty in subjects with severe asthma: a comparison of 3-year follow-up results from two prospective multicentre studies. Eur Respir J 2017;50(2). 10.1183/13993003.00017-2017.

69. Dougherty RH, Fahy JV. Acute exacerbations of asthma: epidemiology, biology and the exacerbation-prone phenotype. Clin Exp Allergy 2009;39(2):193-202. [PubMed: 19187331]

70. Cates CJ, Bara A, Crilly JA, et al. Holding chambers versus nebulisers for beta-agonist treatment of acute asthma. Cochrane Database Syst Rev 2003;(2). 10.1002/14651858.CD000052.

71. Strauss L, Hejal R, Galan G, et al. Observations on the effects of aerosolized albuterol in acute asthma. Am J Respir Crit Care Med 1997;155(2):454-8. [PubMed: 9032178]

72. McFadden ER, Elsanadi N, Dixon L, et al. Protocol therapy for acute asthma: therapeutic benefits and cost savings. Am J Med 1995;99(6):651-61. [PubMed: 7503089]

73. Krishnan JA, Davis SQ, Naureckas ET, et al. An umbrella review: corticosteroid therapy for adults with acute asthma. Am J Med 2009;122(11):977-91. [PubMed: 19854321]

74. O'Byrne P, Pedersen S, Lamm CJ, et al. Severe Exacerbations and decline in lung function in asthma | American Journal of Respiratory and Critical Care Medicine. Am J Respir Crit Care Med 2008;179:19-24. [PubMed: 18990678]

75. Bai TR, Vonk JM, Postma DS, et al. Severe exacerbations predict excess lung function decline in asthma. Eur Respir J 2007;30(3):452-6. [PubMed: 17537763]

76. Wu AW, Young Y, Skinner EA, et al. Quality of care and outcomes of adults with asthma treated by specialists and generalists in managed care. Arch Intern Med 2001;161(21):2554-60. [PubMed: 11718586]

77. Laforest L, Ganse EV, Devouassoux G, et al. Management of asthma in patients supervised by primary care physicians or by specialists. Eur Respir J 2006;27(1): 42-50. [PubMed: 16387934] 


\section{Common indications for specialist referral}

Alternative pulmonary diagnosis suspected

Asthma diagnosis suspected, but confirmation elusive

Possible occupational asthma

Persistently uncontrolled disease

More than 1 exacerbation in past year

History of life-threatening exacerbation

Difficulty with medication selection

Difficulty managing asthma due to comorbidities

Severe disease requiring specialized therapy

\section{KEY POINTS}

- Asthma may become clinically apparent at any age, but exclusion of diseases that mimic asthma is especially important in older individuals.

- A confident diagnosis of asthma can be made with demonstration of reversible obstruction on spirometry, and the risk of misdiagnosis is higher in the absence of this objective information.

- Inhaled corticosteroids are the cornerstone of pharmacologic asthma treatment of persistent disease, with additional therapies added on the basis of inadequate disease control.

- $\quad$ Patients should be empowered to respond to changing symptoms through use of an asthma action plan.

- $\quad$ Specialist referral is indicated for individuals with severe or difficult-tocontrol asthma; however, most individuals with asthma are successfully managed in the primary care setting. 


\section{Evaluate Alternative Diagnoses}

History and Physical

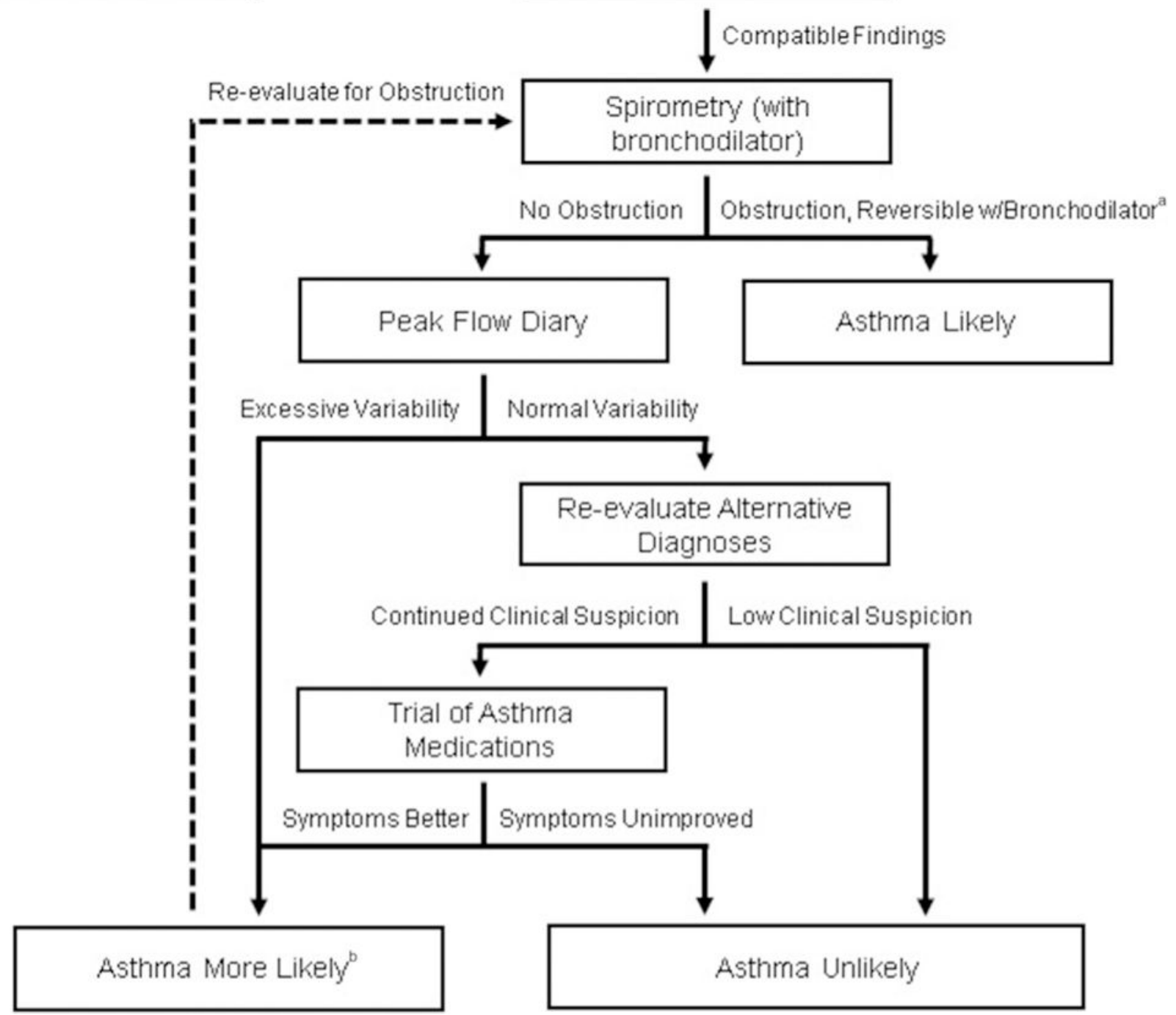

Fig. 1.

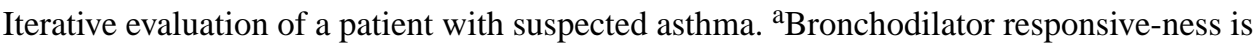
defined as an improvement in $\mathrm{FEV}_{1}$ or $\mathrm{FVC}$ by greater than $12 \%$ and greater than $200 \mathrm{~mL}$. Patients may have improvement that does not meet this threshold and still benefit from bronchodilator therapy. Reversibility implies that spirometry improves to normal after bronchodilator. If only partially reversible, consider possibility of COPD, asthma-COPD

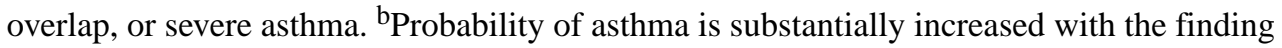
of obstruction at least one time on spirometry; reevaluation should occur at regular intervals. The likelihood of identifying obstruction while already on asthma medications is lower. 
Solicit specific patient concerns

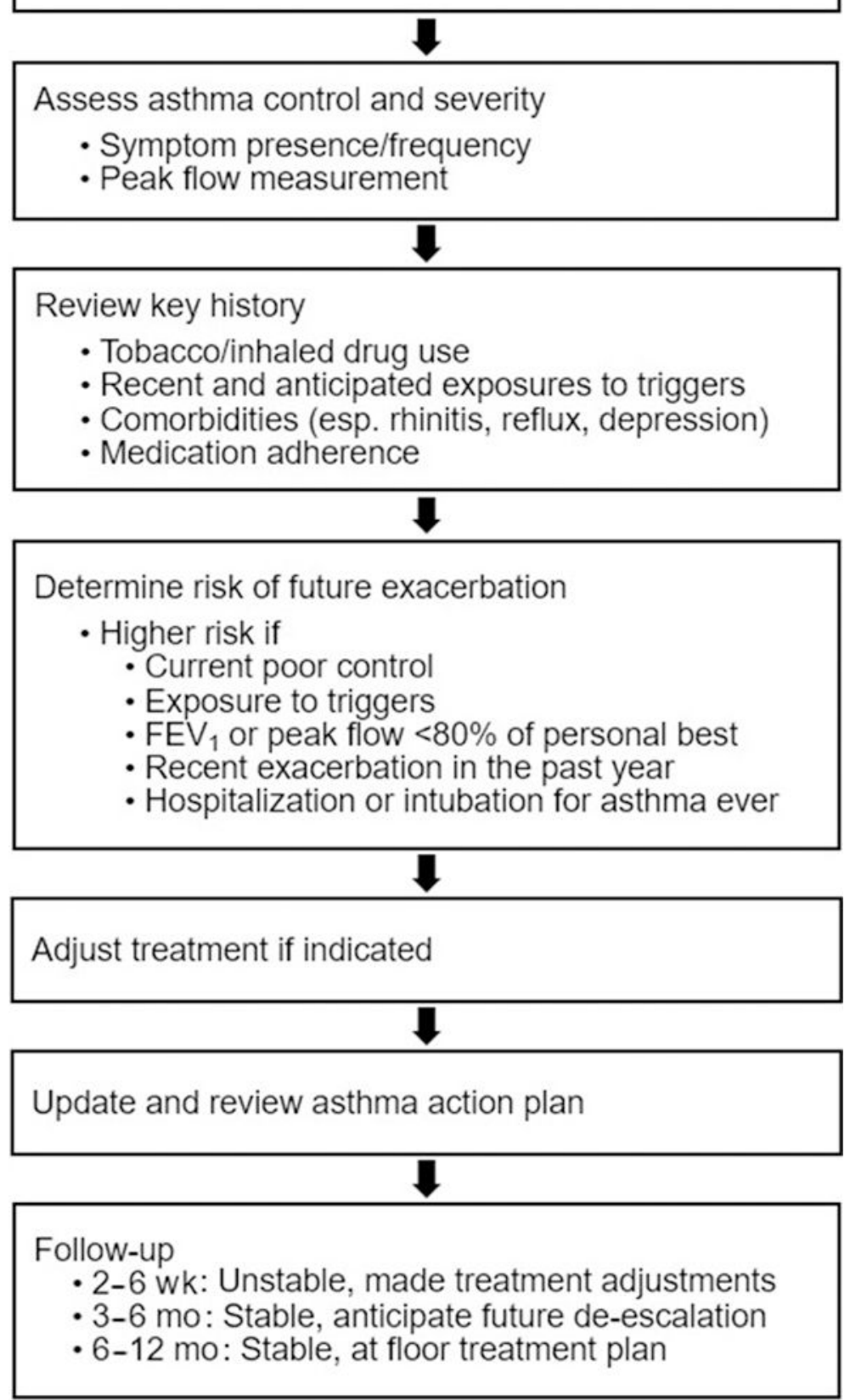

Fig. 2.

Progression of an outpatient visit for asthma. 


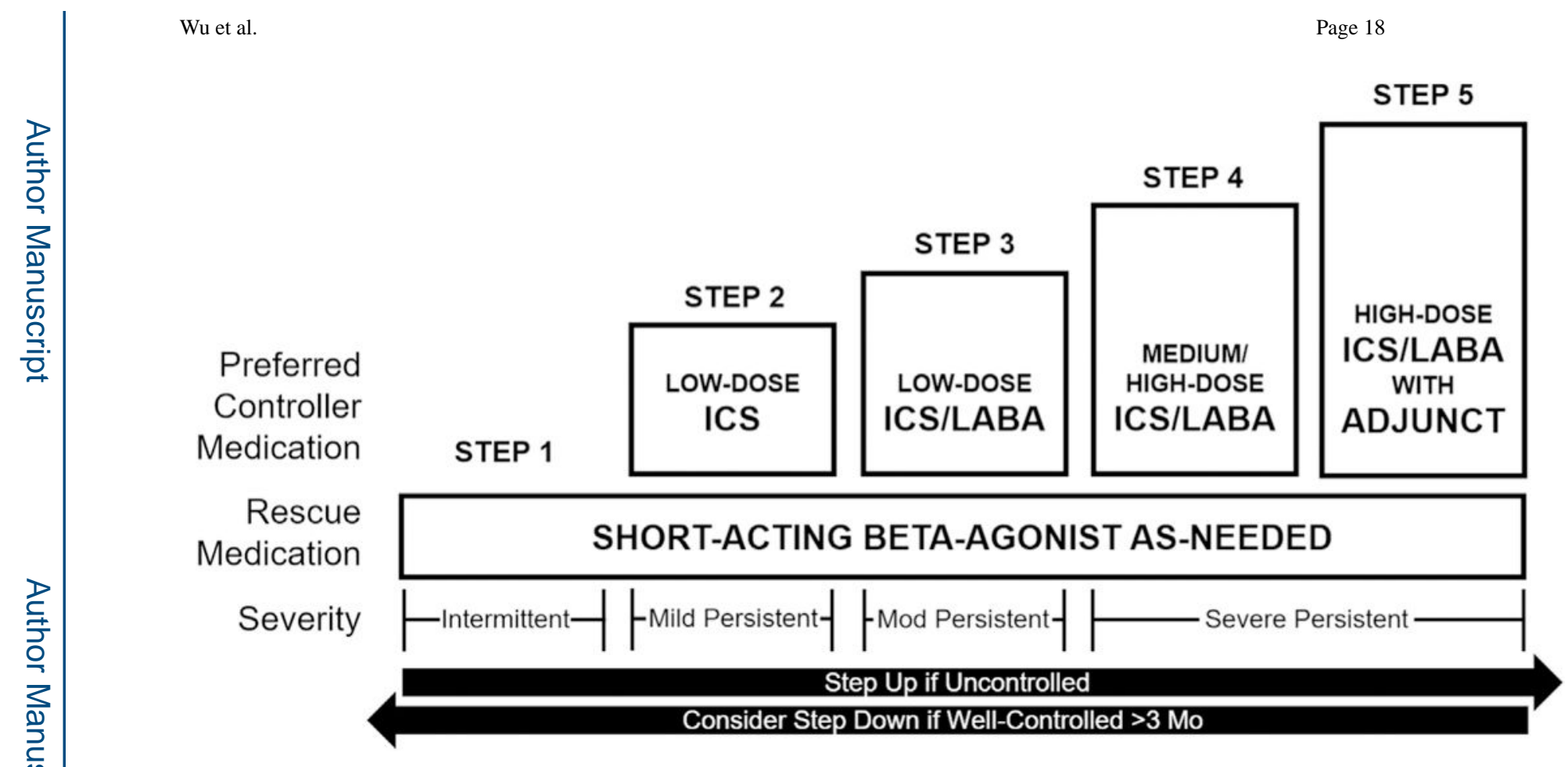

Fig. 3.

Steps of asthma pharmacologic treatment. Adjunct therapies include a long-acting muscarinic antagonist or biologic therapies in selected populations. Immune therapy may be considered for persistent asthma (steps 2-5). Leukotriene modifiers may be considered as an alternative to LABA but are generally less effective. Mod., moderate. (Adapted from Bateman ED, Hurd SS, Barnes PJ, et al. Global strategy for asthma management and prevention: GINA executive summary. Eur Respir J 2008;31(1):157; and National Asthma Education and Prevention Program. Expert panel report 3: guidelines for the diagnosis and management of asthma. Washington (DC): US Department of Health and Human Services, National Heart, Lung, and Blood Institute; 2007. p. 343; with permission.) 


\section{Table 1}

\section{Differential diagnoses in a patient presenting with asthmalike symptoms}

\begin{tabular}{|c|c|}
\hline Condition & Associated Signs and Symptoms \\
\hline $\begin{array}{l}\text { Allergic bronchopulmonary } \\
\text { aspergillosis }\end{array}$ & $\begin{array}{l}\text { Infiltrates, mucus plugging, bronchiectasis, elevated serum total IgE, and sensitization to Aspergillus } \\
\text { (either skin testing or by specific IgE) }\end{array}$ \\
\hline Bronchiectasis & Productive cough, history of recurrent pulmonary infections \\
\hline Carcinoid syndrome & Episodic flushing, diarrhea, emesis \\
\hline COPD & $\begin{array}{l}\text { History of smoking or biomass exposure (especially in those residing in rural areas), irreversible } \\
\text { obstruction on spirometry }\end{array}$ \\
\hline Congestive heart failure & $\begin{array}{l}\text { Pulmonary crackles, lower extremity edema, jugular venous distension, family or personal history of } \\
\text { cardiovascular disease }\end{array}$ \\
\hline Eosinophilic bronchitis & Chronic cough, upper airway symptoms, no hyperresponsiveness \\
\hline $\begin{array}{l}\text { Eosinophilic granulomatosis with } \\
\text { polyangiitis }\end{array}$ & Migratory pulmonary infiltrates, concurrent sinus disease, antineutrophil cytoplasmic antibodies \\
\hline Foreign body aspiration & Localized area of wheeze, segmental atelectasis on computed tomography (CT) scan \\
\hline Interstitial lung disease (ILD) & $\begin{array}{l}\text { Infiltrates, reticulation, or frank fibrosis on CT scan; signs and symptoms vary with ILD type; } \\
\text { hypersensitivity pneumonitis and cryptogenic organizing pneumonia are types of ILD with atopic } \\
\text { association }\end{array}$ \\
\hline Postnasal drip & History of rhinitis and sinusitis, but no variable airflow obstruction \\
\hline Tracheal stenosis/ tracheomalacia & Tracheal narrowing on CT scan, history of intubations \\
\hline $\mathrm{VCD}$ & $\begin{array}{l}\text { Sudden onset of dyspnea, prominent inspiratory wheezing, blunting of the inspiratory limb of the flow- } \\
\text { volume loop }\end{array}$ \\
\hline
\end{tabular}


Table 2

Common asthma triggers and suggested remediation strategies

\begin{tabular}{|ll|}
\hline Trigger $^{\boldsymbol{a}}$ & Strategies \\
\hline Ambient air pollution & Remain indoors during poor air quality days \\
\hline Certain foods & Test for food-specific allergies, avoidance \\
\hline Cigarette smoke & Smoking cessation assistance, home smoking ban \\
\hline Cockroaches & Sweep and vacuum regularly, use roach traps \\
\hline Combustion smoke & Avoid use of wood-burning fireplaces \\
\hline Dust mites & Use mattress and pillowcase covers, avoid down-filled pillows and blankets, wash bedding regularly \\
\hline Emotional distress & Address comorbid depression, involve behavioral specialists \\
\hline Fragrances & Avoidance \\
\hline Indoor air pollution & Reduce source exposure (eg, perform maintenance to reduce $\mathrm{NO}_{2}$ from appliances, such as gas stoves and gas \\
\hline holds & Address leaks, reduce home humidity \\
\hline Pets & Remove or keep pets outdoors \\
\hline Pollens & Remain indoors during morning through midday when specific agent is pollinating \\
\hline Weather events (eg, rain, heat) & Remain indoors during weather events \\
\hline
\end{tabular}

${ }^{a}$ Trigger-specific strategies should only be suggested if patient is sensitive to that trigger; each patient will have different patterns of asthma triggers. 